\title{
Mitochondria Abnormalities in Prostate Cancer Cells and Tissue
}

\author{
Heide Schatten $^{*}$ and Amitabha Chakrabarti*
}

*Dept. of Veterinary Pathobiology, University of Missouri-Columbia, Columbia, MO 65211

***The Cleveland Clinic Foundation, Dept. of Cell Biology, NC-1, Cleveland, OH 44195

Prostate cancer is associated with aging and affects $30-40 \%$ of men by age 30-50 with increases to $75 \%$ in men by age 80 . While a number of factors can play a role in the transformation of normal cells to cancerous cells we have previously shown that decreasing hormone levels are primary factors for alterations on cell and molecular levels [1]. We have shown that centrosome and DNA organization is affected in androgen-responsive human LNCaP cells and we have also shown that androgen-induced oxidative stress is associated with multiple mitochondrial modifications in androgen-responsive human LNCaP prostate cancer cells [2]. While mitochondria numbers are increased by androgen treatment, mitochondria functions are decreased. The resultspresented in this paper are focused on altered mitochondrial morphology in androgentreated human LNCaP cells and on mitochondria in an animal model of prostate cancer [3]. Mitochondria in both cases show variable morphologies ranging from elongated mitochondria with dense morphology to mitochondria with swollen cristae and deterioration of membrane integrity. An example of mitochondria deterioration is shown in the figure on the following page which is a TEM image of advanced stages of tumor progression in the transgenic animal model.

Several strategies have been proposed for therapy of prostate cancer which includes treatment with antioxidants to rescue mitochondrial functions from oxidative stress. We have previously shown that alpha-tocopherol will reduce oxidative stress [2]. Our ongoing investigations are focused on genistein, a phytoestrogen enriched in soy food and antioxidant that has beneficial effects on mitochondrial functions [4].

\section{REFERENCES}

[1] Schatten, H., Ripple, M., Balczon, R., Weinduch, R., and Taylor, M. (2000). Journal of Cellular Biochemistry, 76:463-477.

[2] Ripple, M.O., Hagopian, K., Oberly, T., Schatten, H., and Weindruch, R. (1999). Antioxidant and Redox Signaling, Vol 1, No.1, 71-81.

[3] Schatten, H., Wiedemeier, A., Taylor, M., Lubahn, D., Greenberg, M.N., Besch-Williford, C., Rosenfeld, C., Day, K., and Ripple, M. (2000). Biology of the Cell 92:331-340.

[4] Supported by the Cancer Research Center (CRC) and the University of MissouriColumbia. 


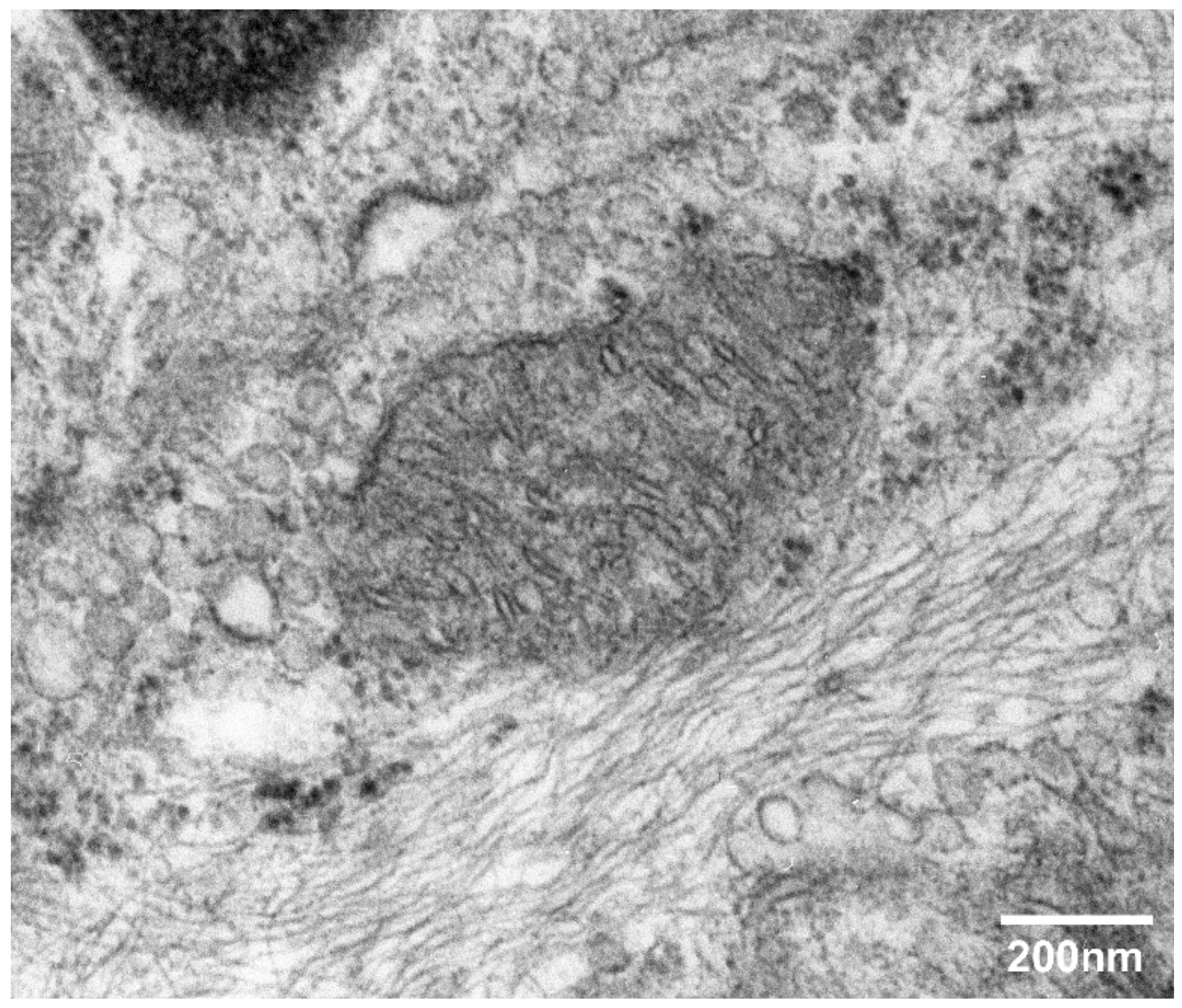

\section{Figure Legend}

TEM image of mitochondria from tissue of advanced stages of prostate cancer in a transgenic animal model. Shown here are swollen cristae and disintegration of mitochondria membranes. 